The FASEB Journal express article 10.1096/fj.03-0009fje. Published online August 1, 2003.

\title{
Neutrophil C5a receptor and the outcome in a rat model of sepsis
}

Ren-Feng Guo, ${ }^{* \dagger}$ Niels C. Riedemann, ${ }^{*}$ Kurt D. Bernacki, ${ }^{*}$ Vidya J. Sarma, ${ }^{*}$ Ines J. Laudes, ${ }^{*}$ Jayne S. Reuben, ${ }^{*}$ Ellen M. Younkin, ${ }^{*}$ Thomas A. Neff,* Joseph D. Paulauskis, ${ }^{\dagger}$

Firas S. Zetoune, ${ }^{*}$ and Peter A. Ward

*Department of Pathology, University of Michigan Medical School, Ann Arbor 48109; and

${ }^{\dagger}$ Department of Drug Safety Evaluation, Pfizer Global Research and Development Ann Arbor, Michigan 48105

R.F. Guo and N.C. Riedemann contributed equally to the work.

Corresponding author: Peter A. Ward, M.D., Department of Pathology, The University of Michigan Medical School, 1301 Catherine Road, Ann Arbor, MI 48109-0602. E-mail: pward@umich.edu

\section{ABSTRACT}

Complement fragment 5a (C5a)-C5a receptor (C5aR) signaling plays an essential role in neutrophil innate immunity. Blockade of either the ligand or the receptor improves survival rates in experimental sepsis. In the current study, sepsis was induced in rats by cecal ligation/puncture. Early in sepsis C5aR content on neutrophils significantly dropped, reached the nadir at $24 \mathrm{~h}$ after onset of sepsis, and progressively elevated thereafter. Western-blot, RT-PCR, and confocal microscopy analyses revealed that the loss and re-expression of $\mathrm{C} 5 \mathrm{aR}$ during sepsis might be due, at least in part, to the receptor internalization and reconstitution. The reduction and reconstitution of $\mathrm{C} 5 \mathrm{aR}$ correlate with the loss and restoration of innate immune functions of blood neutrophils (chemotaxis and reactive oxygen species production), respectively. Quantitative measurements of $\mathrm{C} 5 \mathrm{aR}$ on blood neutrophils are highly predictive of survival or death during sepsis. These data suggest that neutrophil $\mathrm{C} 5 \mathrm{aR}$ content represents an essential component of an efficient defense system in sepsis and may serve as a prognostic marker for the outcome.

Key words: innate immunity • polymorphonuclear cells • complement

ctivation of the complement system is an effective defense mechanism against invading
microorganisms. However, accumulating evidence indicates that excessive activation
may lead to compromised host defenses (1). There is strong evidence for complement activation both in human sepsis and in septic animals (2-5), as reflected by elevated plasma levels of anaphylatoxins, such as $\mathrm{C} 3 \mathrm{a}, \mathrm{C} 4 \mathrm{a}$, and $\mathrm{C} 5 \mathrm{a}$. In vivo blockade of $\mathrm{C} 5 \mathrm{a}$ has been shown to significantly improve survival rates in experimental sepsis $(3,6,7)$, indicating that an excessive amount of $\mathrm{C} 5 \mathrm{a}$ in sepsis exerts harmful effects. Recently, we have obtained evidence that excessive production of $\mathrm{C} 5 \mathrm{a}$ is associated with the loss of the respiratory burst in neutrophils, thymocyte apoptosis, and hemostatic defects in a rat model of CLP-induced sepsis (7-9). C5a exerts its effects through $\mathrm{C} 5 \mathrm{a}$ receptor $(\mathrm{C} 5 \mathrm{aR})(10,11)$, which belongs to the rhodopsin family of 
G-protein-coupled receptors with seven transmembrane segments. C5aR signaling has been shown to be pertussis toxin-sensitive as well as pertussis toxin-resistant, depending on the different $\mathrm{G}$ proteins that couple with the receptor (12-16). C5aR expression was originally described on myeloid cells, such as neutrophils (17), eosinophils (10), basophils, and monocytes $(18,19)$. However, there is compelling evidence that C5aR is also present on a variety of nonmyeloid cells in many organs, especially in the lung and the liver $(20,21)$. It has been noted that C5aR levels in tissues are elevated in the setting of inflammation. For instance, in a mouse model of CLP-induced sepsis C5aR expression is markedly increased in lung, liver, kidney, and heart, associated with up-regulation of C5aR mRNA. In this model, systemic blockade of C5aR with anti-C5aR antibody significantly improved survival rates (22). The pathophysiological importance of $\mathrm{C} 5 \mathrm{aR}$ is reinforced by anti-inflammatory activities of a $\mathrm{C} 5 \mathrm{a}$ receptor antagonist in reverse-passive Arthus reaction and endotoxic shock in rats $(23,24)$.

C5aR is ubiquitously present on a variety of cell types and is especially present in abundance on human neutrophils (17). C5aR plays an essential role in E. coli-induced oxidative burst and phagocytosis in human neutrophils (25). The fundamental roles of neutrophils in killing invading microorganisms are seriously compromised in sepsis $(7,26,27)$. This dysfunction has been recently linked to defects in $\mathrm{C} 5 \mathrm{a}-\mathrm{C} 5 \mathrm{aR}$ signaling in neutrophils. During experimental sepsis, blood neutrophils have shown a diminished ability to bind $\mathrm{C} 5 \mathrm{a}$, impaired chemotactic responses to $\mathrm{C} 5 \mathrm{a}$, and a loss of $\mathrm{H}_{2} \mathrm{O}_{2}$ production $(7,28)$. All these defects can be significantly improved after systemic blockade of C5a. In septic patients, a significant loss of C5aR content on blood neutrophils has been observed, associated with a marked decrease in C5a-induced chemotaxis (29). To elucidate the mechanisms for $\mathrm{C} 5 \mathrm{aR}$ alteration and ensuing functional changes during sepsis, we monitored the C5aR expression on neutrophils after onset of sepsis. C5aR on neutrophils internalized at early stage of sepsis and reconstituted later. In this study, we were able to establish, for the first time, a strong linkage between reconstitution of C5aR on neutrophils and survival of septic animals, suggesting that C5aR may be a critical component in neutrophil action during sepsis, dictating the fate of septic subjects.

\section{MATERIALS AND METHODS}

\section{Preparation and characterization of antibody against rat C5aR}

A 38-amino acid peptide spanning the N-terminus of the rat C5aR (MDPISNDSSEITYDYSDGTPNPDMPADGVYIPKMEPGD) was synthesized using an Applied Biosystems (Foster City, CA) 430A peptide synthesizer. The peptide was then coupled to keyhole limpet hemocyanin by the glutaraldehyde method and used for the immunization of rabbits and the production of immunoreactive anti-sera. Staining of this antibody with blood neutrophils resulted in a significant peak shift by flow cytometric analysis, when compared to preimmune IgG staining.

\section{Rat model of cecal ligation and puncture}

Male Long-Evans specific-pathogen-free rats (275-300 mg; Harlan, Indianapolis, IN) were used in all studies. Anesthesia was induced by intraperitoneal administration of ketamine $(20 \mathrm{mg} / 100$ mg body wt). After the abdomen was shaved and a topical disinfectant was applied, a 2-cm midline incision was made and the cecum was identified and ligated below the ileocecal valve, 
with care being taken not to occlude the bowel. The cecum was then subjected to a single through-and-through perforation with an 18-gauge needle. After the bowel was repositioned, the abdominal incision was closed in layers with plain gut surgical suture 4-0 (Ethicon, Inc., Somerville, NJ) and metallic clips. Sham animals underwent the same procedure except for cecal ligation and puncture. Before and after surgery, animals had unlimited access to food and water. Animals receiving anti-C5a antibody treatment were injected intravenously at the time of the CLP procedure with $500 \mu \mathrm{g}$ rabbit anti-rat C5a IgG [against the carboxyl-terminal region; purified and characterized as described previously (30)] or with $500 \mu \mathrm{g}$ of preimmune rabbit IgG.

\section{Flow cytometric analysis}

C5aR content on blood neutrophils was evaluated by indirect immunofluorescence staining of whole blood using an established lyse/wash procedure (BD PharMingen, San Diego, CA). Flow cytometric analysis was carried out immediately after blood collection. One-hundred microliters of rat whole blood were first incubated with $1 \mu \mathrm{g}$ rat Fc Block (BD Pharmingen) for 15 min and then stained with $10 \mu \mathrm{l}$ of anti-C5aR serum for $30 \mathrm{~min}$ at room temperature. After being washed, the cells were labeled with Fluorescein Isothiocyanate (FITC)-conjugated goat anti-rabbit IgG (1:50) (Biosource Inc., Santa Clarita, CA). Erythrocytes were lysed for $10 \mathrm{~min}$ by addition of $1 \times$ fluorescent activated-substrate conversion (FASC) lysing solution (BD Pharmingen). After being washed, the leukocytes were resuspended in a fixation solution (1\% paraformaldehyde in PBS with $0.1 \%$ sodium azide). Granulocytes were gated by the typical forward and side light scatter profiles. The same-gated population has been proven to be granulocytes by staining of whole blood with a FITC-labeled rat granulocyte marker, HIS48 (BD Pharmingen). It revealed that $\geq 90 \%$ of gated cells were granulocytes. The cells were analyzed on a flow cytometer (Coulter Corp., Miami, FL).

\section{Isolation of rat blood neutrophils}

Whole blood from rats was drawn into syringes containing the anti-coagulant citrate dextrose (ACD; Baxter Health Care, Dearfield, IL). Neutrophils were isolated using Ficoll-Paque gradient centrifugation (Pharmacia Biotech, Uppsala, Sweden) and dextran sedimentation. After hypotonic lysis of residual RBC, the neutrophils were used for further studies.

\section{Western blot analysis}

Neutrophils $\left(2 \times 10^{6}\right)$ were dissolved in $100 \mu$ of $2 \times$ Laemmli sample buffer lysis buffer. Thirty microliters of whole cell lysate were electrophoresed in a denaturing $10 \%$ polyacrylamide gel and then transferred to a nitrocellulose membrane. Nonspecific binding sites were blocked with TBST (40 mM Tris, $\mathrm{pH} 7.6 ; 300 \mathrm{mM} \mathrm{NaCl}, 0.1 \%$ Tween 20), containing 5\% nonfat dry milk for $12 \mathrm{~h}$ at $4^{\circ} \mathrm{C}$. The membrane was then incubated with anti-rat $\mathrm{C} 5 \mathrm{aR}$ serum at a 1:100 dilution. After five washes in TBST, the membrane was incubated in a 1:10,000 dilution of horseradish peroxidase-conjugated donkey anti-rabbit IgG (Amersham Pharmacia Biotech, Piscataway, NJ). The membrane was developed by enhanced chemiluminescence technique according to the protocol of the manufacturer (Amersham Pharmacia Biotech). 


\section{Detection of C5aR mRNA by semiquantitative RT-PCR}

Total RNA was isolated from isolated neutrophils with the Trizol method (Life Technologies Inc., Rockville, MD) according to the instructions of the manufacturer. Digestion of any contaminating DNA was achieved by treatment of samples with RQ1 RNase-Free DNase (Promega Corp., Madison, WI). Reverse transcription was performed with $5 \mu \mathrm{g}$ RNA using the Superscript II RNase $\mathrm{H}^{-}$Reverse Transcriptase (Gibco-BRL; Life Technologies Inc., Grand Island, NY) according to the protocol of the manufacturer. PCR was then performed with primers for C5aR: 5' primer, 5'-TAT AGT CCT GCC CTC GCT CAT-3'; and 3' primer, 5'-TCA CCA CTT TGA GCG TCT TGG-3'. The primers were designed for a 409-bp cDNA amplification in the middle region of rat C5aR cDNA (nucleotides 373-781). The primers for the "housekeeping" gene GAPDH were 5' primer, 5'-GCC TCG TCT CAT AGA CAA GAT G-3'; and 3' primer, 5'-CAG TAG ACT CCA CGA CAT AC-3'. After a "hot-start" for 5 min at $94^{\circ} \mathrm{C}$, 25 35 cycles were used for amplification with a melting temperature of $94^{\circ} \mathrm{C}$, an annealing temperature of $60^{\circ} \mathrm{C}$, and an extending temperature of $72^{\circ} \mathrm{C}$, each for $1 \mathrm{~min}$, followed by a final extension at $72^{\circ} \mathrm{C}$ for $8 \mathrm{~min}$. RT-PCR products were confirmed by electrophoresis of samples in $1.2 \%$ agarose gel. In some cases, reverse transcriptase was omitted in order to rule out contaminating DNA being responsible for any results. To ensure that DNA was detected within the linear part of the amplification curves, PCR was performed using different cycle numbers for $\mathrm{C} 5 \mathrm{aR}$ and GAPDH primers. Thirty cycles of amplification for $\mathrm{C} 5 \mathrm{aR}$ and 25 cycles for GAPDH were found to be in the linear range of PCR amplifications.

\section{Immunocytochemistry and confocal microscopy}

Isolated neutrophils were plated on glass coverslips (Fisher, No.1 thickness) fastened to the bottom of punched-out wells of 12-well plates (diameter $22.6 \mathrm{~mm}$ ). Coverslips were sequentially coated with poly-D-lysine and calfskin collagen to promote cell adhesion. The cells were fixed with $4 \%$ paraformaldehyde followed by a permeablization step with $10 \%$ methanol. Nonspecific binding sites were blocked with $0.1 \%$ gelatin for 20 min and with $4 \%$ normal goat serum for 30 min. The cells were incubated with either anti-C5aR serum (1:10) or preimmune serum (1:10) for $2 \mathrm{~h}$ on ice. The cells were then washed and incubated with Alexa-488 Fab fragment of goat anti-rabbit IgG (1:200; Molecular Probes; Eugene, OR). The cells were covered with SlowFade solution (Molecular Probes) and visualized using a confocal fluorescence microscope (Zeiss LSM 510, Jana, Germany). Both projection view and optical sections were developed electronically and processed digitally. Optical scanning and digital processing of the images were performed to determine the topographic distribution of the Alexa Fluor-conjugated IgG in the cells.

\section{Chemotaxis assay}

After neutrophil isolation, cells were fluorescein labeled with Calcein AM (Molecular Probes). Labeled neutrophils were then loaded into the upper chambers of 96-well chemotaxis minichambers (Neuroprobe, Cabin John, MD). Lower chambers were loaded with rat recombinant $\mathrm{C} 5 \mathrm{a}$ or buffer alone. The upper and lower chambers were separated by a polycarbonate membrane of $3-\mu \mathrm{m}$ porosity (Neuroprobe). Minichambers were incubated for 30 min at $37^{\circ} \mathrm{C}$. Cells that did not migrate were carefully wiped away, and the number of cells that migrated through the polycarbonate filters to the lower surface was measured by cytofluorometry 
(Spectra MAX Gemini XS; Molecular Devices, Sunnyvale, CA). Samples were measured in quadruplicates. The ratio between the number of cells that migrated through the membrane in the presence of C5a and the buffer is defined as the chemotactic index (31).

\section{Intracellular reactive oxygen species}

The intracellular formation of reactive oxygen species (ROS) was evaluated by using the fluorescent probe CM- $\mathrm{H}_{2}$ DCFDA (Molecular Probe). Isolated neutrophils were treated with 100 $\mathrm{nM}$ C5a for $15 \mathrm{~min}$ at $37^{\circ} \mathrm{C}$, followed by incubation with $10 \mu \mathrm{M} \mathrm{CM}-\mathrm{H}_{2} \mathrm{DCFDA}$ for $30 \mathrm{~min}$ at $37^{\circ} \mathrm{C}$. Fluorescence generation associated with ROS production was measured by cytofluorometry (Spectra MAX Gemini XS; Molecular Devices). Buffer controls were run in parallel.

\section{Statistical analysis}

In groups with equal variances, data sets were analyzed using one-way ANOVA, and individual group means were then compared with the Student-Newman-Keuls multiple comparison test. In groups containing unequal variances, Kruskal-Wallis ANOVA was performed, followed by Dunnett's method for multiple comparisons. All values were expressed as the mean \pm SE. Significance was assigned where $P<0.05$. For percent change between groups, values obtained from negative controls were subtracted from each data point. A proportional hazard modeling was used to compare survival between treatment groups. Survival analysis was performed with SAS 8.0 statistical software (SAS Institute, Cary, NC).

\section{RESULTS}

\section{C5aR expression on blood neutrophils during sepsis}

As shown in a recent study, C5aR levels on blood neutrophils in septic patients are significantly lower than those in healthy donors (29). To understand the dynamics of C5aR expression on neutrophils during sepsis, C5aR content on blood neutrophils was quantitatively evaluated by flow cytometric analysis $0,4,12,24,36$, and $48 \mathrm{~h}$ after the onset of CLP-induced sepsis. Blood neutrophils from control animals showed a positive staining with anti-C5aR, whereas very limited staining was seen with preimmune serum (Fig.1A). During experimental sepsis, C5aR content on blood neutrophils was sharply decreased as early as $4 \mathrm{~h}$ after onset of CLP, reaching a nadir at $24 \mathrm{~h}$. The intensity of C5aR staining was almost as low as the staining found with preimmune serum, suggesting a very low level of C5aR expression on neutrophils at this time point. Interestingly, C5aR levels increased progressively thereafter (Fig. 1A $)$. Preimmune serum showed no positive staining of neutrophils at the various time points. In vitro studies have demonstrated that $\mathrm{C} 5 \mathrm{a}$ can rapidly induce $\mathrm{C} 5 \mathrm{aR}$ internalization on human neutrophils, which cause considerable loss of C5aR content on the cell surface $(32,33)$.

\section{Role of C5a in sepsis-induced loss of C5aR content on neutrophils}

To address whether excessive $\mathrm{C} 5 \mathrm{a}$ in sepsis contributed to the loss of C5aR content on neutrophils, systemic C5a was blocked by an intravenous infusion of $500 \mu \mathrm{g}$ anti-C5a rabbit IgG immediately after the onset of sepsis. A companion group of CLP rats was similarly treated with 
$500 \mu \mathrm{g}$ preimmune IgG. C5aR content on neutrophils was analyzed $12 \mathrm{~h}$ after CLP. Anti-C5a treatment preserved $\mathrm{C} 5 \mathrm{aR}$ content on neutrophils, resulting in $65 \%$ increase $(P<0.05)$ in comparison to preimmune IgG treatment (Fig. 1B).

\section{Internalization and reconstitution of $\mathrm{C5aR}$ on neutrophils during sepsis}

In CLP-induced sepsis, C5a expression is markedly enhanced in lung, liver, kidney, and heart in a transcription-dependent manner (22). To determine the mechanism by which $\mathrm{C} 5 \mathrm{aR}$ content on neutrophils is regulated during sepsis, we evaluated C5aR protein and mRNA levels in purified neutrophils 0, 24, and $48 \mathrm{~h}$ after CLP. Western-blot analysis of whole cell lysates of rat neutrophils revealed a band with $\sim 44-\mathrm{kDa}$ position, characteristic of rat C5aR ( Fig. $2 A)$. Western blotting of the same samples with anti-GAPDH shows equal loading. Densitometric quantification of $\mathrm{C} 5 \mathrm{aR}$ protein levels revealed that there were no significant changes in $\mathrm{C} 5 \mathrm{aR}$ protein levels in neutrophils from CLP rats when compared to control neutrophils $(n=4)$. C5aR PCR products from 30-cycle amplification and GAPDH PCR products from 25-cycle amplification, which have been found to be in the linear range of the amplifying reactions, are displayed in Fig. $2 B$. C5aR mRNA levels showed no differences in blood neutrophils isolated 0 , 24, and $48 \mathrm{~h}$ after the onset of sepsis (Fig. $2 \mathrm{~B}$ ). To visualize C5aR changes in neutrophils during sepsis, we conducted confocal fluorescence microscopy analysis. As shown in Fig. $2 C$, in control (Ctr) cells $\mathrm{C} 5 \mathrm{aR}$ showed a uniform distribution in the cell periphery, indicative of membrane staining. In contrast, a diffuse pattern of staining was found in the cytoplasmic compartment in $24 \mathrm{~h}$ CLP neutrophils, accompanied by disappearance of the peripheral cell staining, indicative of C5aR internalization. In neutrophils $48 \mathrm{~h}$ after CLP, C5aR expression appeared to be in both membrane and cytoplasm of cells, suggesting that $\mathrm{C} 5 \mathrm{aR}$ reconstitution was occurring. These data suggest that C5aR on neutrophils is internalized at the early stages of sepsis and is re-expressed thereafter.

\section{Association of functional changes of neutrophils with C5aR levels on neutrophils}

The level of $\mathrm{C} 5 \mathrm{aR}$ has been shown to be related to the functional responses of neutrophils. In septic patients, a significant loss of C5aR content on blood neutrophils was associated with a marked decrease in C5a-induced chemotaxis (29). To study whether the neutrophil function is associated with C5aR levels in sepsis, control neutrophils and cells isolated from rats 24 and $48 \mathrm{~h}$ after CLP were chosen to represent the three different levels of C5aR expression. We first evaluated the effect of phorbol 12-myristate 13-acetate (PMA) on C5aR content on neutrophils, as PMA is a strong inducer of C5aR internalization (34). As shown in Fig. 3A, 100 nM PMA strongly diminished the $\mathrm{C} 5 \mathrm{aR}$ staining on control neutrophils. No further internalization was observed when 24 h-CLP neutrophils were treated with PMA. However, significant loss of C5aR was found in PMA-treated neutrophils obtained from 48 h-CLP rats (Fig. 3A). As expected, 10 $\mathrm{nM}$ C5a induced a vigorous chemotactic response for control neutrophils with a chemotactic index (CI) of $9.05 \pm 1.28$ (Fig. $3 B$ ). C5a chemotaxis was severely impaired for cells from $24 \mathrm{~h}-$ CLP animals $(\mathrm{CI}=2.62 \pm 0.55)$. Chemotaxis responsiveness was significantly improved in $48 \mathrm{~h}$ CLP cells in comparison to $24 \mathrm{~h}-\mathrm{CLP}$ cells $(\mathrm{CI}=4.95 \pm 1.34 ; P<0.05)$. Another manifestation of functional recovery for $48 \mathrm{~h}$-CLP neutrophils was obtained by assessing C5a-induced ROS production in these cells (Fig. 3C). C5a (100 nM) evoked a marked increase in ROS generation in control cells. This C5a-induced response was completely lost in 24 h-CLP cells. However, 48 h-CLP cells showed a statistically significant response to C5a as reflected by ROS formation 
(Fig. $3 C ; P<0.05$ vs. buffer control). These data indicate that loss in C5aR content on neutrophils during sepsis is associated with defective functional responses of neutrophils.

\section{C5aR levels on neutrophils predicts the lethal outcome of septic animals}

The data above lead us to the speculation that $\mathrm{C} 5 \mathrm{aR}$ reconstitution may affect the overall outcome of septic animals. To test this hypothesis, we assessed the survival of CLP rats and in parallel C5aR levels on blood neutrophils $36 \mathrm{~h}$ after CLP. Twenty three out of 37 rats survived $36 \mathrm{~h}$ after CLP (Fig. $4 A$ ). Blood samples were taken from these survivors' tail vein for assessing C5aR levels on blood neutrophils. Based on the overall median (1.03), we divided these animals into two groups: high levels of C5aR group $(n=11)$ and low levels of C5aR group $(n=12)($ Fig. $\underline{4 B})$. All the animals $(n=11 ; 100 \%)$ with higher levels of C5aR survived, whereas only 4 out of $12(33 \%)$ animals with lower levels of C5aR survived during a 7 day interval (Fig. $4 C$ ). The difference between the outcomes of these two groups was statistically significant $(P=0.001$ by proportional hazards modeling). Thus, the level of C5aR surface expression $36 \mathrm{~h}$ after onset of sepsis was positively correlated with the survival of the individual animals.

\section{DISCUSSION}

In sepsis, the innate immune system is severely impaired, as reflected by excessive inflammatory mediator production, complement activation, and functional defects in phagocytic cells $(26,27$, $35,36)$. At the late stage of sepsis, neutrophils suffer a "dormant" phase in the sense that the major features of neutrophil function including chemotaxis, respiratory burst activity, and ability for bacterial killing are seriously compromised. Accumulating evidence suggests that excessive production of $\mathrm{C} 5 \mathrm{a}$ in sepsis may contribute to the loss of C5a binding on neutrophils, decreased chemotactic responsiveness, defective oxidative burst, and impaired bacteriocidal activity (7, 27, $28,37)$. Blockade of $\mathrm{C} 5 \mathrm{a}$ and its counter partner C5aR improves the outcome of septic animals, underscoring the importance of $\mathrm{C} 5 \mathrm{a}-\mathrm{C} 5 \mathrm{aR}$ signaling in the innate immunity $(7,22)$. The crucial role of $\mathrm{C} 5 \mathrm{aR}$ signaling was directly revealed by using a whole blood model of inflammation (25). Blockade of C5a or C5aR drastically reduced E. coli-induced blood neutrophil oxidative burst and completely abolished opsonization and phagocytosis (25). It is well known that neutrophils quickly dash into a hyperactive stage after onset of sepsis, which may be attributable to multiorgan failure $(26,38-40)$. Thus, interception of C5a-C5aR pathway in sepsis may limit neutrophil-mediated tissue injury, resulting in a beneficial outcome. We here suggest another possibility for beneficial intervention, namely the preservation of neutrophil function at the late stage of sepsis.

C5aR on neutrophils serves as a powerful tool for clearance of excessive circulating C5a (33), perhaps to attenuate the inflammatory responses. Previous studies have suggested that, after binding of $\mathrm{C} 5 \mathrm{a}$ to $\mathrm{C} 5 \mathrm{aR}$ on neutrophils, the ligand/receptor complex is rapidly internalized, with C5aR being recycled to the cell surface $(32,41,42)$. In LPS-induced endotoxic shock, binding of ${ }^{125} \mathrm{I}-\mathrm{C} 5$ a to neutrophils was significantly decreased, suggestive of down-regulation of C5aR (43). However, recent studies show that C5a can also bind with high affinity to a newly identified receptor, C5L2, which appears to be expressed in various cell types including neutrophils (4446). Such findings imply the limited validity of data derived from measurement of C5aR using binding of ${ }^{125} \mathrm{I}$ - or fluorescein-labeled C5a. In the current study, by direct detection of C5aR with anti-C5aR antibody, we were able to observe the dynamic pattern of C5aR expression on 
neutrophils in vivo during sepsis. $\mathrm{C} 5 \mathrm{aR}$ on neutrophils was internalized at an early stage of sepsis $(<24 \mathrm{~h}$ ), and its re-expression could be detected on the cell surface $>36 \mathrm{~h}$ after CLP (Fig. $\underline{1 A})$. The absence of changes in protein and mRNA levels in neutrophils at various time points of sepsis suggests that the re-expression of C5aR may be due, at least in part, to C5aR recycling. In striking contrast, during CLP-induced sepsis C5aR mRNA and protein levels were up-regulated in various organs, implying that the expression of $\mathrm{C} 5 \mathrm{aR}$ on neutrophils may differ from that found in organs (22). The pattern of C5aR expression on neutrophils is perfectly concordant with the C5a binding curve during sepsis (28), indicating that the number of C5aR sites is critical for $\mathrm{C} 5 \mathrm{a}$ binding to neutrophils. A rapid decrease in C5aR content on neutrophils was, at least in part, caused by systemically appearing C5a, because blockade of C5a significantly preserved C5aR content on blood neutrophils (Fig. $1 B$ ). It is possible that other inflammatory mediators that cause down-regulation of $\mathrm{C} 5 \mathrm{aR}$ may also exist in the circulation during sepsis.

Decreased surface content of $\mathrm{C} 5 \mathrm{aR}$ on neutrophils has been seen in critically ill and anergic septic patients and in HIV patients $(29,47,48)$. In the latter group, decreased level of C5aR on neutrophils was associated with reduced $\mathrm{C} 5 \mathrm{a}$-induced chemotactic responses and elevated peripheral levels of C5a des Arg (48). Similarly, septic neutrophils displayed transiently diminished $\mathrm{C} 5 \mathrm{aR}$ content and a concomitant decrease in $\mathrm{C} 5 \mathrm{a}$-induced chemotaxis. There were also decreased levels of IL-8 receptors (CXC R1 and CXC R2) on septic neutrophils; however, no change was observed in chemotaxis to IL-8 (29). As seen in the same study, IL-8 receptors but not C5aR gene expression decreased in parallel to receptor down-regulation. These data highlight the differences between $\mathrm{C} 5 \mathrm{aR}$ and other G-protein coupled chemokine receptors with respect to the mechanism of down-regulation and functional responses. C5aR expression was shown to be regulated in a manner that differed from fMLP receptor, CR1, CR3, and Fc receptors $(32,49)$. In contrast to C5aR, fMLP receptor levels increased on neutrophils in humans with sepsis $(40,50)$. Upon stimulation of their ligands, although both receptors undergo an internalization independent of arrestin, dynamin, and clathrin [the internalization machinery that is utilized by the $\beta_{2}$-adrenergic receptor $\left(\beta_{2} \mathrm{AR}\right)$ ] (42), re-expression of fMLP receptor is predominantly regulated by granule motion, whereas $\mathrm{C} 5 \mathrm{aR}$ employs a different, not yet specified, mechanism $(32,50)$.

At $24 \mathrm{~h}$ after the onset of sepsis, almost all the C5aR on neutrophils internalized, as demonstrated by a very low level of anti-C5aR binding and unresponsiveness to $100 \mathrm{nM}$ PMA (Fig. $1 \mathrm{~A}$ and Fig. 3A). Soon after this time point, survival curve dropped steeply (Fig. 4A). Presumably, all deceased animals did not get a chance to march into a phase in which C5aR content and functions of neutrophils were recovering. At the late stage of sepsis $(>24 \mathrm{~h}), \mathrm{C} 5 \mathrm{aR}$ on septic neutrophils started to undergo a functional recovery, as reflected by increased content of C5aR, associated with enhanced ROS production as well as chemotaxis. It should be pointed out that a uniform pattern of C5aR expression with a single peak was observed at all time points of CLP by using flow cytometry analysis (data not shown), representing the whole neutrophil population with homogeneous $\mathrm{C} 5 \mathrm{aR}$ levels. We have previously shown that anti-C5a treatment significantly preserves $\mathrm{H}_{2} \mathrm{O}_{2}$ production and chemotactic activity of neutrophils in sepsis $(7,28)$, suggesting a potential role of low levels of $\mathrm{C} 5 \mathrm{aR}$ in neutrophil dysfunction. Thus, we were able to establish a linkage between $\mathrm{C} 5 \mathrm{aR}$ content on neutrophils and their functional capability, in response to C5a, to migrate toward the sites of inflammation and to fight bacterial infection during sepsis. Furthermore, there was a positive correlation between the level of C5aR re-expression on septic neutrophils and survival of individual animals. The correlation was such that all animals with 
$\mathrm{C} 5 \mathrm{aR}$ levels higher than the overall median at $36 \mathrm{~h}$ survived, whereas out of the animals with $\mathrm{C} 5 \mathrm{aR}$ levels lower than the median $67 \%$ died within the next 3 days.

Based on these findings, we postulate that higher levels of $\mathrm{C} 5 \mathrm{aR}$ on neutrophils at the late stage of sepsis assemble an efficient defense system for bacterial killing, resulting in a positive outcome of septic animals. Most of the clinical trials for sepsis that targeted an attenuation of the inflammatory response failed (51). It seems reasonable to use such a strategy during the early onset of sepsis to suppress the overwhelming inflammatory reaction in a hyper-responsive phase. However, the pathogenesis of sepsis is a complex, dynamic course. In the case of neutrophils, it endures "hyperreactive," "dormant," and "recovering" stages. Our data suggest that, at the "dormant" or "recovering" phase, a treatment to facilitate the recovery of C5aR levels and neutrophil function could be a promising therapeutic strategy for sepsis. However, it can not be excluded that higher levels of C5aR may be due to reduced levels of mediators (e.g., C5a) that cause $\mathrm{C} 5 \mathrm{aR}$ internalization during sepsis. C5aR levels on neutrophils may serve as a prognostic marker for the outcome in sepsis. Our present study for the first time demonstrates a linkage between $\mathrm{C} 5 \mathrm{aR}$ on blood neutrophils and survival or death, showing a close correlation of innate immune functions of neutrophils and their content of C5aR in vivo.

\section{ACKNOWLEDGMENTS}

This work was supported by research grants from the National Institutes of Health (GM-61656 and HL-31963 to P. A. Ward) and a research grant from the American Lung Association (RG057-N to R. F. Guo). We thank Beverly Schumann and Peggy Otto for secretarial assistance.

\section{REFERENCES}

1. Darville, T., Giroir, B., and Jacobs, R. (1993) The systemic inflammatory response syndrome (SIRS): immunology and potential immunotherapy. Infection 21, 279-290

2. de Boer, J. P., Creasey, A. A., Chang, A., Roem, D., Eerenberg, A. J., Hack, C. E., and Taylor, F. B., Jr. (1993) Activation of the complement system in baboons challenged with live Escherichia coli: correlation with mortality and evidence for a biphasic activation pattern. Infect. Immun. 61, 4293-4301

3. Smedegard, G., Cui, L. X., and Hugli, T. E. (1989) Endotoxin-induced shock in the rat. A role for C5a. Am. J. Pathol. 135, 489-497

4. Bengtson, A., and Heideman, M. (1988) Anaphylatoxin formation in sepsis. Arch. Surg. 123, 645-649

5. Nakae, H., Endo, S., Inada, K., Takakuwa, T., Kasai, T., and Yoshida, M. (1994) Serum complement levels and severity of sepsis. Res. Commun. Chem. Pathol. Pharmacol. 84, $189-195$

6. Stevens, J. H., O'Hanley, P., Shapiro, J. M., Mihm, F. G., Satoh, P. S., Collins, J. A., and Raffin, T. A. (1986) Effects of anti-C5a antibodies on the adult respiratory distress syndrome in septic primates. J. Clin. Invest. 77, 1812-1816 
7. Czermak, B. J., Sarma, V., Pierson, C. L., Warner, R. L., Huber-Lang, M., Bless, N. M., Schmal, H., Friedl, H. P., and Ward, P. A. (1999) Protective effects of C5a blockade in sepsis. Nat. Med. 5, 788-792

8. Guo, R. F., Huber-Lang, M., Wang, X., Sarma, V., Padgaonkar, V. A., Craig, R. A., Riedemann, N. C., McClintock, S. D., Hlaing, T., Shi, M. M., et al. (2000) Protective effects of anti-C5a in sepsis-induced thymocyte apoptosis. J. Clin. Invest. 106, 1271-1280

9. Laudes, I. J., Chu, J. C., Sikranth, S., Huber-Lang, M., Guo, R. F., Riedemann, N., Sarma, J. V., Schmaier, A. H., and Ward, P. A. (2002) Anti-c5a ameliorates coagulation/fibrinolytic protein changes in a rat model of sepsis. Am. J. Pathol. 160, 1867-1875

10. Gerard, N. P., Hodges, M. K., Drazen, J. M., Weller, P. F., and Gerard, C. (1989) Characterization of a receptor for C5a anaphylatoxin on human eosinophils. J. Biol. Chem. 264, 1760-1766

11. Gerard, N. P., and Gerard, C. (1991) The chemotactic receptor for human C5a anaphylatoxin. Nature 349, 614-617

12. Shirato, M., Takahashi, K., Nagasawa, S., and Koyama, J. (1988) Different sensitivities of the responses of human neutrophils stimulated with immune complex and C5a anaphylatoxin to pertussis toxin. FEBS Lett. 234, 231-234

13. Siciliano, S. J., Rollins, T. E., and Springer, M. S. (1990) Interaction between the C5a receptor and $\mathrm{Gi}$ in both the membrane-bound and detergent-solubilized states. J. Biol. Chem. 265, 19568-19574

14. Amatruda, T. T., III, Gerard, N. P., Gerard, C., and Simon, M. I. (1993) Specific interactions of chemoattractant factor receptors with G-proteins. J. Biol. Chem. 268, 10139-10144

15. Hu, M. H., Wang, M., Browning, D. D., Mukaida, N., and Ye, R. D. (1999) NF-kappaB activation is required for $\mathrm{C} 5 \mathrm{a}$-induced interleukin-8 gene expression in mononuclear cells. Blood 93, 3241-3249

16. Shum, J. K., Allen, R. A., and Wong, Y. H. (1995) The human chemoattractant complement C5a receptor inhibits cyclic AMP accumulation through Gi and Gz proteins. Biochem. Biophys. Res. Commun. 208, 223-229

17. Chenoweth, D. E., and Hugli, T. E. (1978) Demonstration of specific C5a receptor on intact human polymorphonuclear leukocytes. Proc. Natl. Acad. Sci. USA 75, 3943-3947

18. Kurimoto, Y., de Weck, A. L., and Dahinden, C. A. (1989) Interleukin 3-dependent mediator release in basophils triggered by C5a. J. Exp. Med. 170, 467-479

19. Werfel, T., Oppermann, M., Schulze, M., Krieger, G., Weber, M., and Gotze, O. (1992) Binding of fluorescein-labeled anaphylatoxin C5a to human peripheral blood, spleen, and bone marrow leukocytes. Blood 79, 152-160 
20. Haviland, D. L., McCoy, R. L., Whitehead, W. T., Akama, H., Molmenti, E. P., Brown, A., Haviland, J. C., Parks, W. C., Perlmutter, D. H., and Wetsel, R. A. (1995) Cellular expression of the $\mathrm{C} 5 \mathrm{a}$ anaphylatoxin receptor $(\mathrm{C} 5 \mathrm{aR})$ : demonstration of $\mathrm{C} 5 \mathrm{aR}$ on nonmyeloid cells of the liver and lung. J. Immunol. 154, 1861-1869

21. Schieferdecker, H. L., Schlaf, G., Jungermann, K., and Gotze, O. (2001) Functions of anaphylatoxin $\mathrm{C} 5 \mathrm{a}$ in rat liver: direct and indirect actions on nonparenchymal and parenchymal cells. Int. Immunopharmacol. 1, 469-481

22. Riedemann, N. C., Guo, R. F., Neff, T. A., Laudes, I. J., Keller, K. A., Sarma, V. J., Markiewski, M. M., Mastellos, D., Strey, C. W., Pierson, C. L., et al. (2002) Increased C5a receptor expression in sepsis. J. Clin. Invest. 110, 101-108

23. Strachan, A. J., Shiels, I. A., Reid, R. C., Fairlie, D. P., and Taylor, S. M. (2001) Inhibition of immune-complex mediated dermal inflammation in rats following either oral or topical administration of a small molecule C5a receptor antagonist. Br. J. Pharmacol. 134, 17781786

24. Strachan, A. J., Woodruff, T. M., Haaima, G., Fairlie, D. P., and Taylor, S. M. (2000) A new small molecule $\mathrm{C} 5 \mathrm{a}$ receptor antagonist inhibits the reverse-passive Arthus reaction and endotoxic shock in rats. J. Immunol. 164, 6560-6565

25. Mollnes, T. E., Brekke, O. L., Fung, M., Fure, H., Christiansen, D., Bergseth, G., Videm, V., Lappegard, K. T., Kohl, J., and Lambris, J. D. (2002) Essential role of the C5a receptor in E coli-induced oxidative burst and phagocytosis revealed by a novel lepirudin-based human whole blood model of inflammation. Blood 100, 1869-1877

26. Goya, T., Morisaki, T., and Torisu, M. (1994) Immunologic assessment of host defense impairment in patients with septic multiple organ failure: relationship between complement activation and changes in neutrophil function. Surgery 115, 145-155

27. Zimmerman, J. J., Shelhamer, J. H., and Parrillo, J. E. (1985) Quantitative analysis of polymorphonuclear leukocyte superoxide anion generation in critically ill children. Crit. Care Med. 13, 143-150

28. Huber-Lang, M., Sarma, V. J., Lu, K. T., McGuire, S. R., Padgaonkar, V. A., Guo, R. F., Younkin, E. M., Kunkel, R. G., Ding, J., Erickson, R., et al. (2001) Role of C5a in multiorgan failure during sepsis. J. Immunol. 166, 1193-1199

29. Seely, A. J., Naud, J. F., Campisi, G., Giannias, B., Liu, S., DiCarlo, A., Ferri, L. E., Pascual, J. L., Tchervenkov, J., and Christou, N. V. (2002) Alteration of chemoattractant receptor expression regulates human neutrophil chemotaxis in vivo. Ann. Surg. 235, 550559

30. Huber-Lang, M. S., Sarma, J. V., McGuire, S. R., Lu, K. T., Guo, R. F., Padgaonkar, V. A., Younkin, E. M., Laudes, I. J., Riedemann, N. C., Younger, J. G., et al. (2001) Protective effects of anti-C5a peptide antibodies in experimental sepsis. FASEB J. 15, 568-570 
31. Guo, R. F., Ward, P. A., Hu, S. M., McDuffie, J. E., Huber-Lang, M., and Shi, M. M. (1999) Molecular cloning and characterization of a novel human CC chemokine, SCYA26. Genomics 58, 313-317

32. Van Epps, D. E., Simpson, S., Bender, J. G., and Chenoweth, D. E. (1990) Regulation of $\mathrm{C} 5 \mathrm{a}$ and formyl peptide receptor expression on human polymorphonuclear leukocytes. $J$. Immunol. 144, 1062-1068

33. Oppermann, M., and Gotze, O. (1994) Plasma clearance of the human C5a anaphylatoxin by binding to leucocyte C5a receptors. Immunology 82, 516-521

34. Bock, D., Martin, U., Gartner, S., Rheinheimer, C., Raffetseder, U., Arseniev, L., Barker, M. D., Monk, P. N., Bautsch, W., Kohl, J., et al. (1997) The C terminus of the human C5a receptor (CD88) is required for normal ligand-dependent receptor internalization. Eur. J. Immunol. 27, 1522-1529

35. Bone, R. C. (1996) Sir Isaac Newton, sepsis, SIRS, and CARS. Crit. Care Med. 24, 1125 1128

36. Faist, E., Schinkel, C., and Zimmer, S. (1996) Update on the mechanisms of immune suppression of injury and immune modulation. World J. Surg. 20, 454-459

37. Koch, T., Annuss, C., Schiefer, H. G., van Ackern, K., and Neuhof, H. (1997) Impaired bacterial clearance after activation of the complement and coagulation systems. Shock 7, 4248

38. Botha, A. J., Moore, F. A., Moore, E. E., Kim, F. J., Banerjee, A., and Peterson, V. M. (1995) Postinjury neutrophil priming and activation: an early vulnerable window. Surgery 118, 358-364; discussion 364-355

39. Botha, A. J., Moore, F. A., Moore, E. E., Fontes, B., Banerjee, A., and Peterson, V. M. (1995) Postinjury neutrophil priming and activation states: therapeutic challenges. Shock 3, $157-166$

40. Solomkin, J. S., Cotta, L. A., Brodt, J. K., Hurst, J. W., and Ogle, C. K. (1984) Neutrophil dysfunction in sepsis. III. Degranulation as a mechanism for nonspecific deactivation. $J$. Surg. Res. 36, 407-412

41. Naik, N., Giannini, E., Brouchon, L., and Boulay, F. (1997) Internalization and recycling of the C5a anaphylatoxin receptor: evidence that the agonist-mediated internalization is modulated by phosphorylation of the C-terminal domain. J. Cell Sci. 110, 2381-2390

42. Gilbert, T. L., Bennett, T. A., Maestas, D. C., Cimino, D. F., and Prossnitz, E. R. (2001) Internalization of the human $\mathrm{N}$-formyl peptide and $\mathrm{C} 5 \mathrm{a}$ chemoattractant receptors occurs via clathrin-independent mechanisms. Biochemistry 40, 3467-3475 
43. Goldman, D. W., Enkel, H., Gifford, L. A., Chenoweth, D. E., and Rosenbaum, J. T. (1986) Lipopolysaccharide modulates receptors for leukotriene B4, C5a, and formyl-methionylleucyl-phenylalanine on rabbit polymorphonuclear leukocytes. J. Immunol. 137, 1971-1976

44. Kalant, D., Cain, S. A., Maslowska, M., Sniderman, A. D., Cianflone, K., and Monk, P. N. (2003) The chemoattractant receptor-like protein C5L2 binds the C3a des-Arg77/acylationstimulating protein. J. Biol. Chem. 278, 11123-11129

45. Cain, S. A., and Monk, P. N. (2002) The orphan receptor C5L2 has high affinity binding sites for complement fragments C5a and C5a des-Arg(74). J. Biol. Chem. 277, 7165-7169

46. Ohno, M., Hirata, T., Enomoto, M., Araki, T., Ishimaru, H., and Takahashi, T. A. (2000) A putative chemoattractant receptor, C5L2, is expressed in granulocyte and immature dendritic cells, but not in mature dendritic cells. Mol. Immunol. 37, 407-412

47. Tellado, J. M., McGowen, G. C., and Christou, N. V. (1993) Decreased polymorphonuclear leukocyte exudation in critically ill anergic patients associated with increased adhesion receptor expression. Crit. Care Med. 21, 1496-1501

48. Meddows-Taylor, S., Pendle, S., and Tiemessen, C. T. (2001) Altered expression of CD88 and associated impairment of complement 5a-induced neutrophil responses in human immunodeficiency virus type 1 -infected patients with and without pulmonary tuberculosis. J. Infect. Dis. 183, 662-665

49. Van Epps, D. E., Bender, J. G., Simpson, S. J., and Chenoweth, D. E. (1990) Relationship of chemotactic receptors for formyl peptide and C5a to CR1, CR3, and Fc receptors on human neutrophils. J. Leukoc. Biol. 47, 519-527

50. Tennenberg, S. D., and Solomkin, J. S. (1988) Neutrophil activation in sepsis. The relationship between fmet-leu-phe receptor mobilization and oxidative activity. Arch. Surg. 123, 171-175

51. Cohen, J., Guyatt, G., Bernard, G. R., Calandra, T., Cook, D., Elbourne, D., Marshall, J., Nunn, A., and Opal, S. (2001) New strategies for clinical trials in patients with sepsis and septic shock. Crit. Care Med. 29, 880-886 
Fig. 1
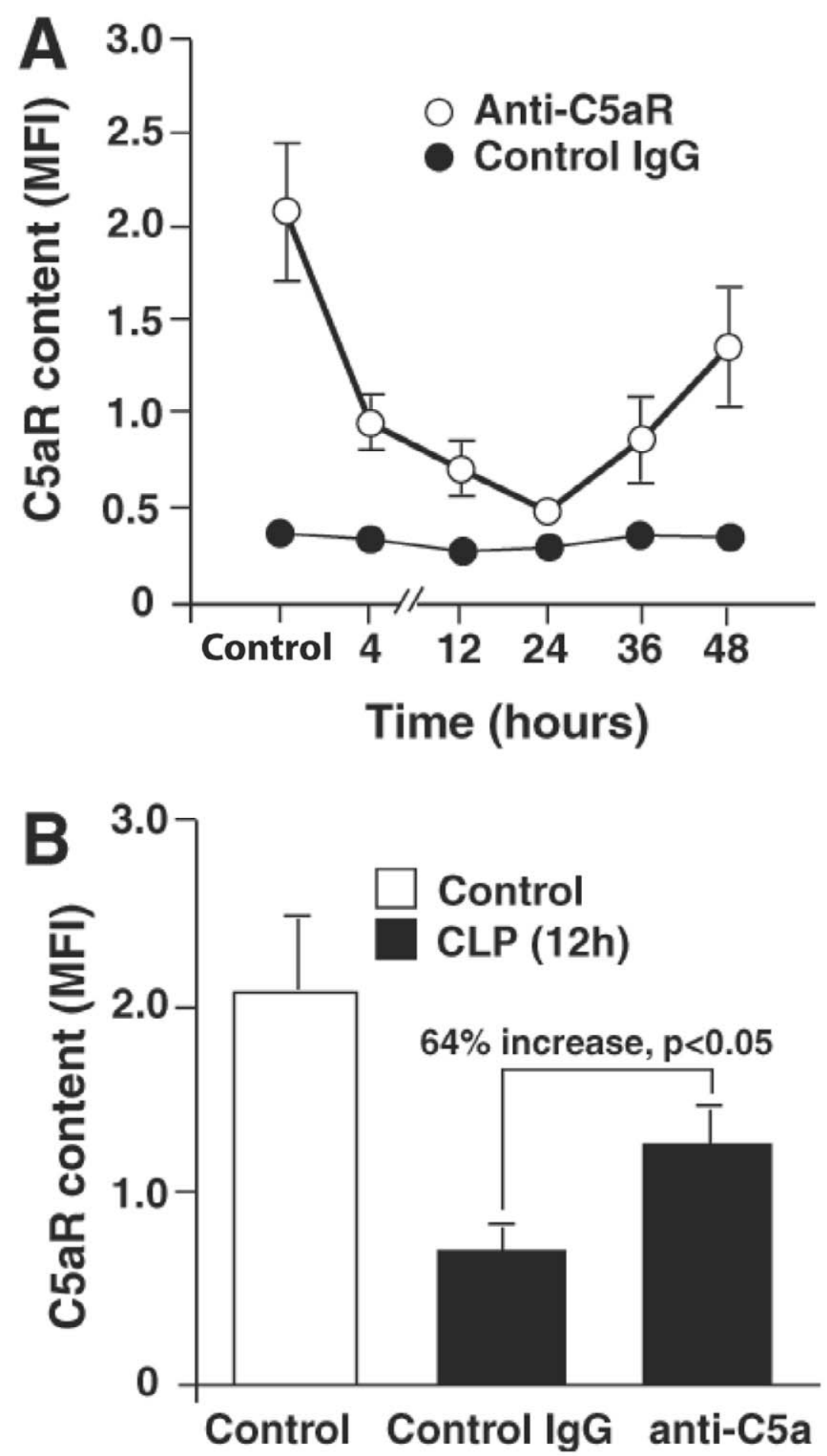

Figure 1. A) C5aR expression on neutrophils during experimental sepsis. Whole blood samples from controls (normal rats) and CLP animals were stained with anti-C5aR rabbit serum or preimmune serum, and C5aR content on blood neutrophils was evaluated by flow cytometric analysis at the times indicated. B) Effect of C5a blockade on C5aR expression in sepsis. C5a was blocked by an intravenous injection of $500 \mu \mathrm{g}$ anti-C5a rabbit IgG immediately after the onset of CLP. Control animals were subjected to sham surgery. C5aR content on blood neutrophils was assessed $12 \mathrm{~h}$ after CLP. Values are means \pm SE $(n=5)$. 
Fig. 2
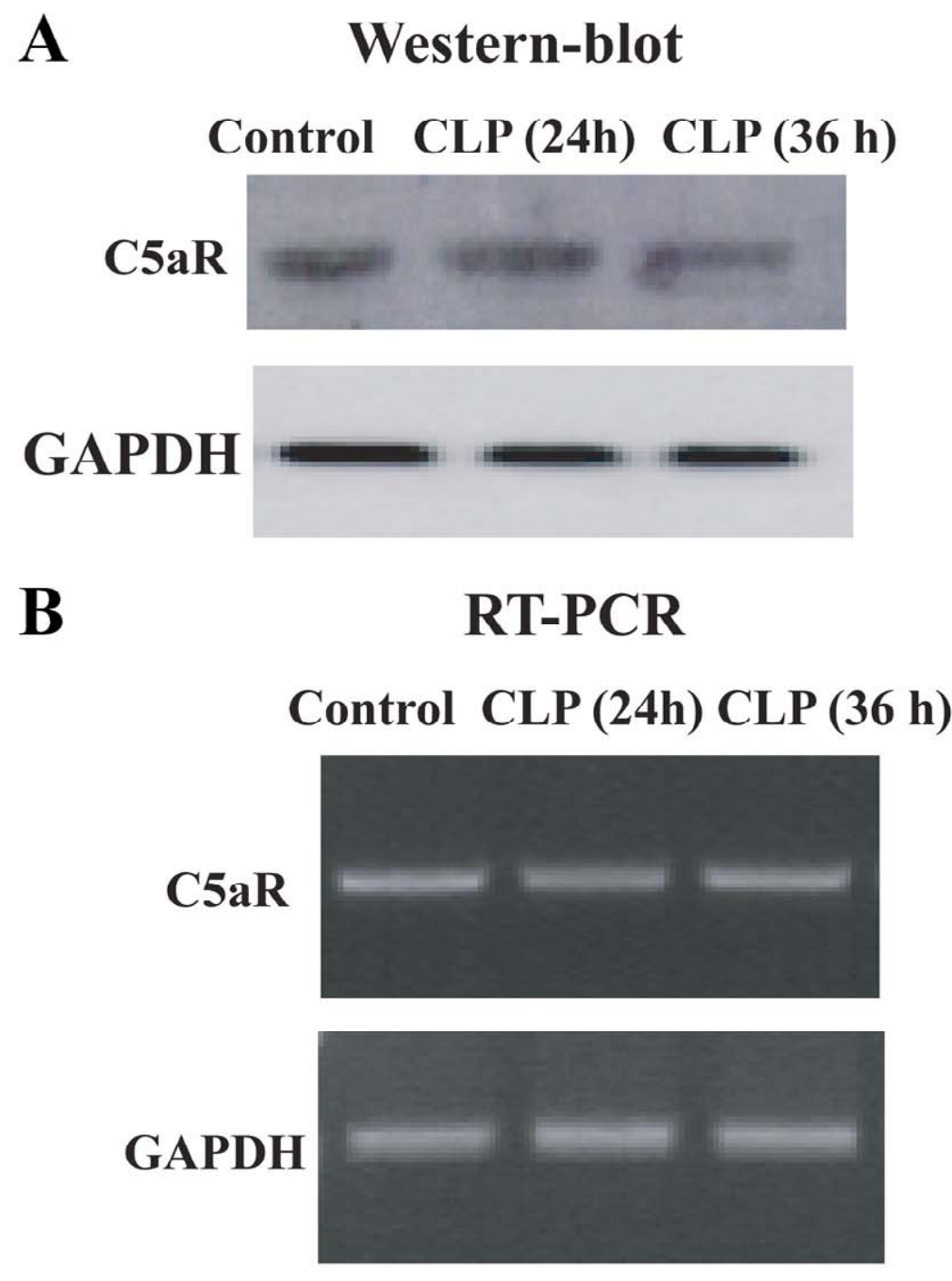

C

\section{Confocal Microscopy}

\section{Control CLP (24h) CLP (48h)}
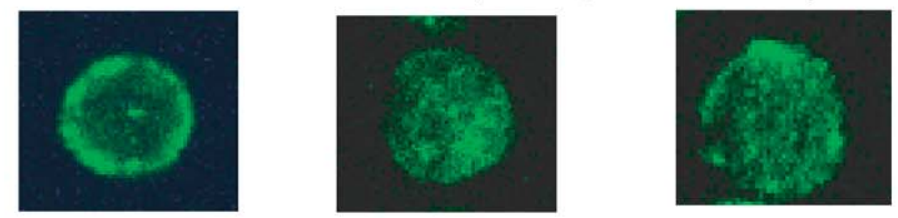

Figure 2. Internalization of C5aR on neutrophils in sepsis. Neutrophils were isolated from whole blood 0,24 , and $48 \mathrm{~h}$ after CLP. Neutrophils from normal rats $(0 \mathrm{~h})$ served as control cells. $\boldsymbol{A}$ ) C5aR protein level was evaluated by Western-blot analysis of the whole cell lysates; the figures are results from 4 separate and independent experiments. $\boldsymbol{B}$ ) RT-PCR was used to assess C5aR mRNA expression in control and septic neutrophils; the figures are results from 3 separate experiments. C) C5aR translocation was visualized by confocal microscopy analysis; the figures are results from 2 separate experiments. 
Fig. 3
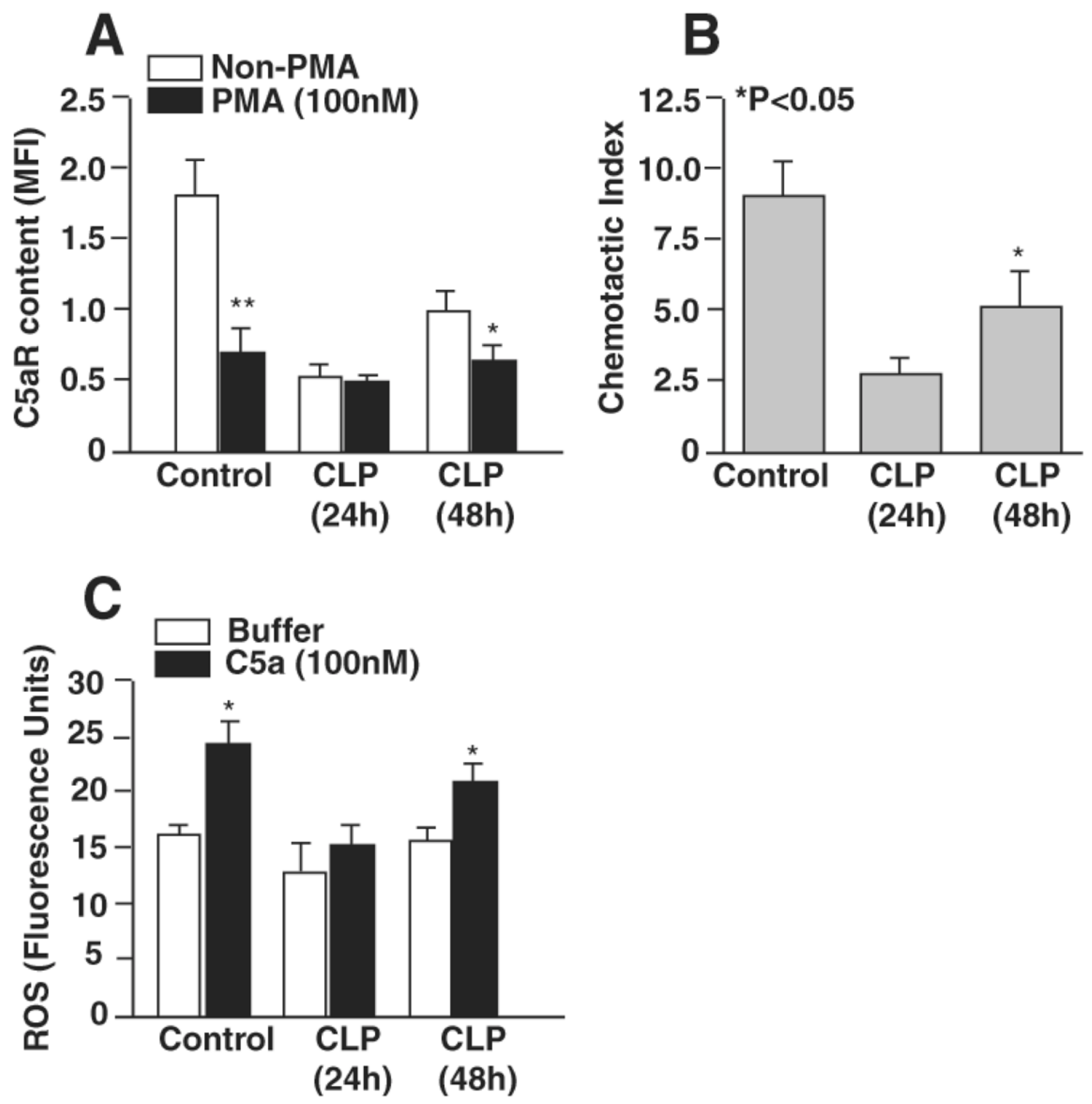

Figure 3. Influence of C5aR levels on the functional responses of neutrophils. Neutrophils were isolated from whole blood 0, 24, and $48 \mathrm{~h}$ after CLP. $\boldsymbol{A}$ ) Control and septic neutrophils were treated with $100 \mathrm{nM}$ PMA, and PMA-induced internalization was evaluated by flow cytometry analysis. $\boldsymbol{B}$ ) Chemotactic responses of control and septic neutrophils to 10 nM C5a were determined by Boyden's chemotaxis assay. $C$ ) Oxidative burst activity was monitored by conversion of dichlorofluorescin to DCF as a measure of ROS production. $* P<0.05$, $* * \mathrm{P}<0.01$ compared with neutrophils in the same group in $\boldsymbol{A}$ and $\boldsymbol{C}$, and compared with septic neutrophils (24 h CLP) in $\boldsymbol{B}$. For each vertical bar, $n=4$. 
Fig. 4
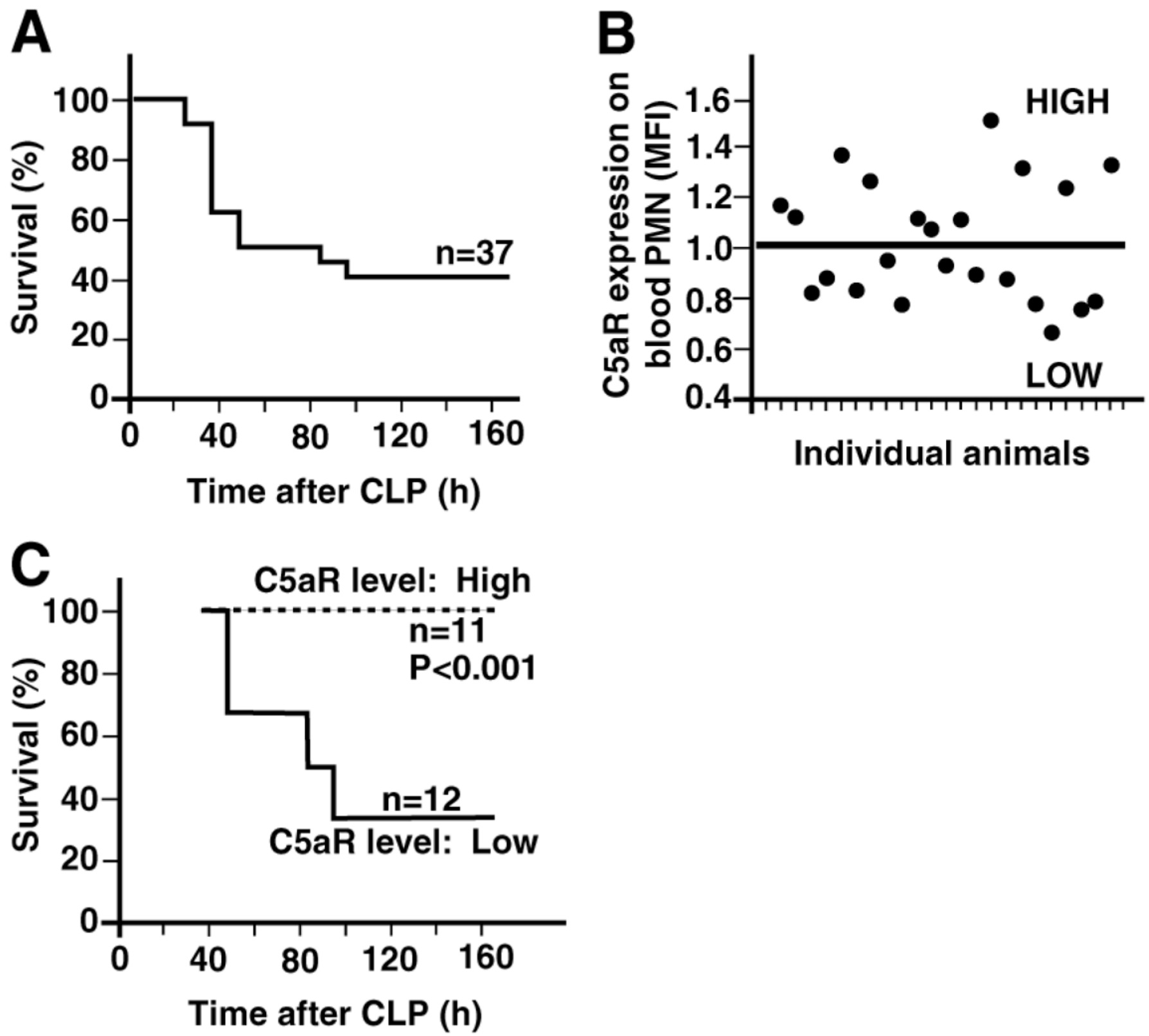

Figure 4. Correlation of C5aR levels on neutrophils with survival. $A$ ) Thirty-seven rats were subjected to CLP procedure, and a survival curve was obtained over a 7 day interval. Blood samples were taken from tail veins $36 \mathrm{~h}$ after CLP, and C5aR levels were evaluated by flow cytometry analysis. B) Based on the median, the animals were divided into two groups: animals with neutrophil C5aR levels higher than median (HIGH) and animals with neutrophil C5aR levels lower than median (LOW). C) Survival of animals from these 2 groups was monitored. 